Article

\title{
Design of Experiment (DOE) Analysis of 5-Cell Stack Fuel Cell Using Three Bipolar Plate Geometry Designs
}

\author{
Tabbi Wilberforce ${ }^{1, *}$ and Abdul Ghani Olabi ${ }^{1,2}$ (D) \\ 1 Mechanical Engineering and Design, Aston Triangle, Aston University, Birmingham B4 7ET, UK; \\ aolabi@sharjah.ac.ae \\ 2 Department of Sustainable and Renewable Energy Engineering, University of Sharjah, Sharjah P.O. Box \\ 27272, UAE \\ * Correspondence: t.awotwe@aston.ac.uk
}

Received: 15 May 2020; Accepted: 28 May 2020; Published: 1 June 2020

\begin{abstract}
The investigation conducted is aimed at establishing the best operational conditions to obtain the best output of a 5-cell stack Proton Exchange Membrane fuel cell (PEMFC) with three different bipolar plate geometries. The work further explores the best input parameters that will yield the maximum voltage, current power as well as fuel efficiency from each of the three designs under investigation. A polarization curve was generated for each of the three designs and a surface response plot developed for each experiment. The work concluded that the spiral design performed very well compared to the other designs under investigation and even existing on the fuel cell market.
\end{abstract}

Keywords: design of experiment; spiral design; bipolar plate; fuel cell; polarization curve

\section{Introduction}

Proton exchange membrane (PEM) fuel cells generate current and voltage using hydrogen gas (fuel) and oxidant (oxygen) as reactant and platinum as catalyst through an electrochemical process [1-3]. The fuel (hydrogen) is introduced into the fuel cell via the anode flow channels while the oxygen/air flows through the cathode flow channels. The hydrogen is broken down into two ions at the anodic region of the fuel cell (hydrogen ions and electrons) using a platinum catalyst as the main inducing factor. The protons (hydrogen ions) then flow through the membrane to the cathodic area of the PEMFC where it meets air, forming the byproduct of the electrochemical reaction [4]. The connection of an external circuit to the fuel cell allow the easy flow of electrons back to the cathode region. The combination of the oxygen, protons and the electrons form the byproduct of the electrochemical reaction which is water. For the fuel cell to function properly, it is recommended that the water is expelled to reduce the possibility of flooding. The high current densities obtained from PEMFC makes them highly recommended as alternative energy generation mediums to fossil fuels. They also have good operating temperature range, between 60 and $80^{\circ} \mathrm{C}$, and have fast response startups. Figure 1 shows a schematic view of the various components forming PEMFC [5]. 

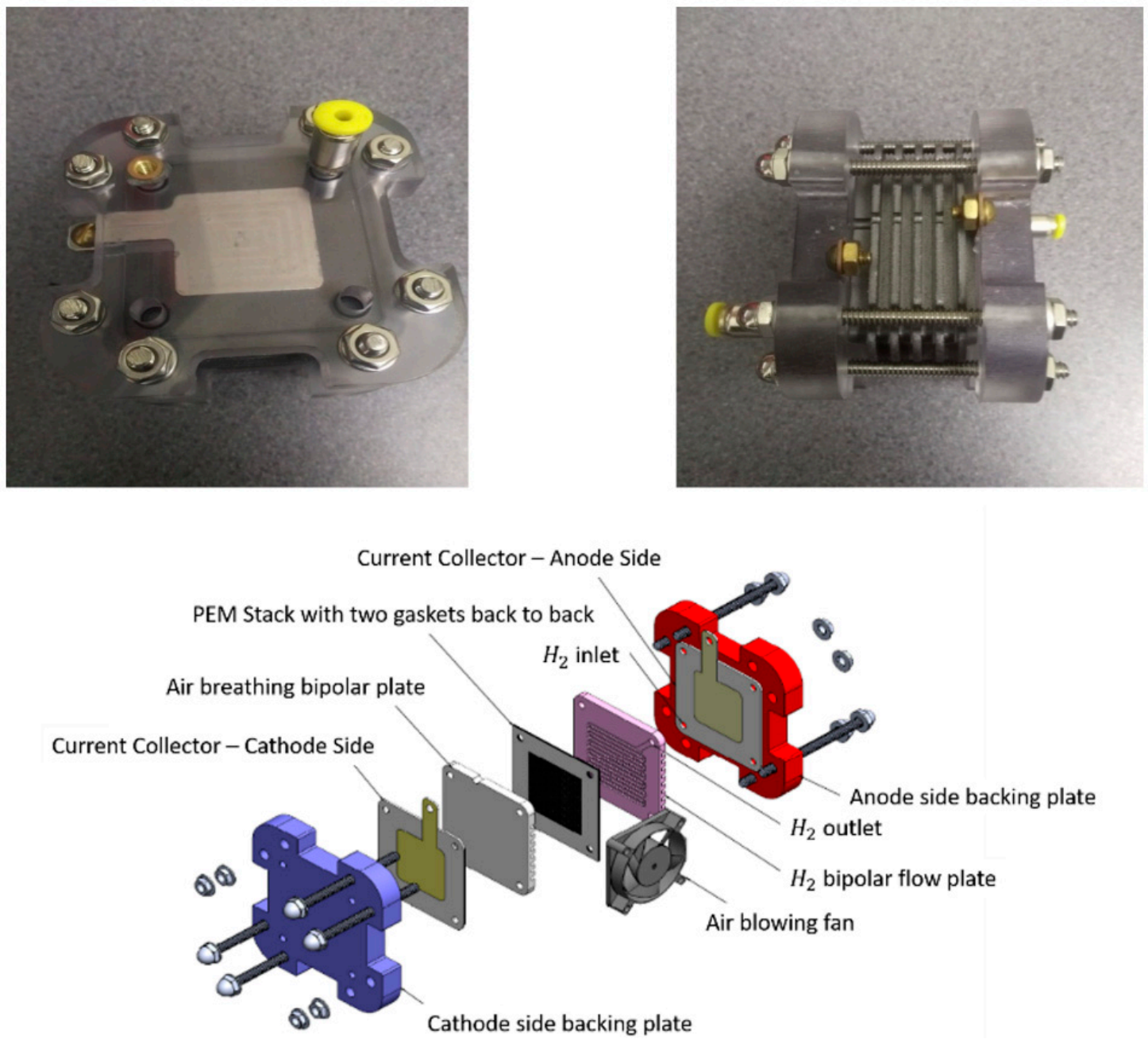

Figure 1. Components in the purchased PEMFC from a US fuel cell store.

Other advantages of fuel cells are: the type of fuel used can be obtained from other mediums, require less maintenance due to less number of moving parts which can lead to wear and tear or produce heat. They also do not need charging and will continue to produce power once the fuel is supplied to it. Fuel cells have their own limitations as well but the common well-known demerit is related to cost. Fuel cells comes in many shapes and forms and each of the type is named according to the electrolyte used in their operation. For fuel cells to fairly compete with existing energy-generation mediums, the cost as well as the weight of the fuel cell must be reduced considerably. Pragmatic methods of enhancing the performance characteristics of any fuel cell involve varying the operational parameters [6]. It is mainly because operational conditions of the cell contribute significantly to the overall current and voltage being generated from the stack. An in-depth knowledge of the best operating conditions for the cell will reduce the cost involved in running the fuel cell, especially knowing the required fuel needed to obtain the maximum cell output. Again, a good understanding of the operational map of fuel cells can contribute to the efficient and judicious usage of all the reactive substances needed to support the cell operate at its maximum potential [7]. It will also reduce the possibility of destroying the fuel cell. Several researches have been conducted on the fuel cell operating conditions to obtain the best output of the fuel cell, but these researches do not consider the surface response and design of experiment (DOE) analysis to predict the optimal conditions for the cell [8]. 


\subsection{Design of Experiment}

DOE software is considered as a numerical method for organizing as well as performing scientific research that involves changing the variables of an experiment to know their impact on any specific response. With the least sample size, maximum information can be obtained simply by controlling the initial variables. DOE is an effective mathematical modelling software to the extent that varying any of the input parameters can predict the impact on any given response. It gives out information based on the impact of different factors on a response variable. In some cases, DOE can be used to predict the optimum settings for those factors. Figure 2 shows the basic steps in any DOE analysis.

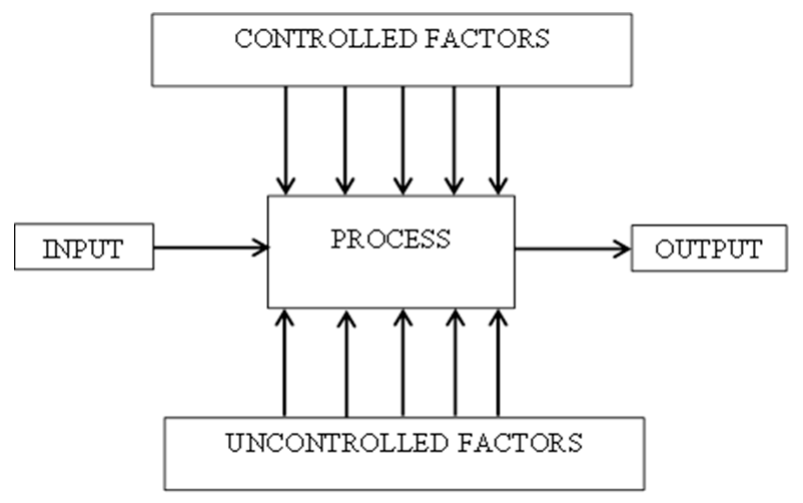

Figure 2. Design of Experiment approach.

Experiments are conducted in most manufacturing companies to enhance the understanding of the products they are manufacturing. This is very important as it determines the input parameter (factors) that leads to the maximum output of the entire manufacturing process. It also influences the target input variable in order to get the desired results. There are several approaches that can be used to conduct an experiment. Most engineers prefer the one-factor-at-a-time (OFAT)/one-variable-at-a-time (OVAT) approach. This method involves engineers varying one input parameter at a given instance while maintaining all other variables. This method has recently been replaced using design of experiment (DOE) because it involves lots of expenses in terms of cost and time to generate little information. The one variable at a time approach also involves some risk as the conductor of the experiment is limited to finding an input variable which will have immense impact on the output but often do not consider that a variation in one parameter will affect the initial input response. It implies that the OVAT approach is not highly reliable, time dependent and does not give the best conditions and does not consider the relationship effects between the process variables [9]. The statistical approach can be used to replace the OVAT experimental approach and this is where DOE becomes very useful. It is a mathematical approach of investigating or modelling a system which includes organizing, performing, analyzing and elucidating data for experiments conducted by the engineering community. It involves designing different tests where changes are carried out on the initial parameters of an experimental activity. The effect of these input variations on any response is carefully analyzed further to determine if the input variable changes the response independently or when combined with other parameters [10]. The effect of different fertilizer on several plots of land was determined by Sir R. Fisher around the 1920s [10]. Design of experiment since then has been used for several purposes in many fields like biology, pharmacy, engineering etc. For nearly 20 years, it has seen an appreciable increase in usage for metal forming and even machining [11], but the most common type of design of experiment is the response surface approach, developed by Box and Wilson in the 1950s [9]. 


\subsection{Surface Response Approach}

This is a set of arithmetic and numerical data analysis method helpful in creating the output parameter under investigation with respect to the initial input parameters that can be controlled. [12,13]. Once the independent variables are determined, the entire process can be repeated to reduce and check for any error. Equation (1) can then be used to represent the response surface.

$$
z=f\left(m_{1}, m_{2}, \ldots \ldots m_{k}\right)
$$

where variables that are unrelated to each other are represented by $k$.

The actual correlation between the variables that are unrelated, and their corresponding response surface can be determined functionally using a polynomial in second order represented by Equation (2).

$$
z=b_{o}+\sum b_{i} m_{i}+\sum b_{i j} m_{i} m_{j}+\sum b_{i i} m_{i i}^{2}+\varepsilon
$$

\subsection{Box-Behnken Design (BBD)}

The well-known response surface method design is the Box-Behnken design (BBD) and it is made up of three level of the various factors represented as $-1,0$ and +1 . The method was conceptualized by Box and Behnken in the year 1960 [14]. It involves combining a two-level factorial design with block designs that that are not completed by means of adding specific number of centre points. Figure 3 shows the Box-Behnken design represented schematically. An advantage of BBD is the fact that they are designed spherically. Again, it is designed to have the factors run only on three levels. BBDs are rotatable, meaning the values of $\mathrm{z}$ are predictable and they are concomitant to the interval between a point from the centre point. Again, for a Box-Behnken design, the important area is similar to the region of operability and does not involve runs because all the factors are either positive one $(+1)$ or negative one $(-1)$ level and these specific regions are described as corner points. It is very beneficial, especially in instances where the corner points signifies costly or inconvenient runs because they are found at the end of the range of the factor levels [14].

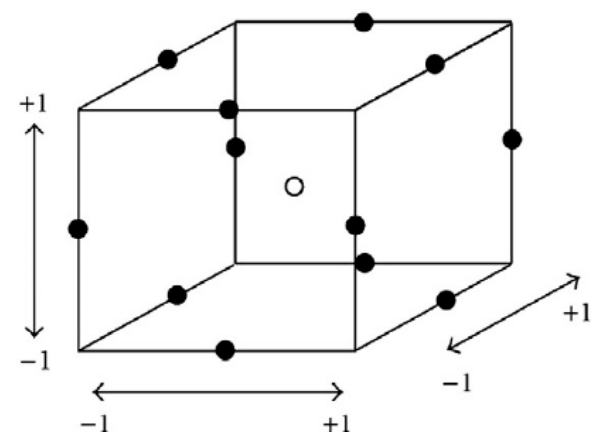

Figure 3. Box-Behnken design.

\subsection{Box-Behnken Designing of Three Factors}

The approach adopted in creating a numerical design for the response, $\mathrm{z}$ as a function of three factors $\left(P_{1}, P_{2}, P_{3}\right)$ by means of integration of finite element modelling and design of experiment approach are as below. The matrix is often dependent on the type of RSM design selected. For Box-Behnken design the coded data matrix is usually between the ranges of $-1,0,+1$ as captured in Table 1. 
Table 1. Box-Behnken-coded data matrix.

\begin{tabular}{cccc}
\hline Runs & $\boldsymbol{P}_{1}$ & $\boldsymbol{P}_{2}$ & $\boldsymbol{P}_{3}$ \\
\hline i & -1 & -1 & 0 \\
ii & 1 & -1 & 0 \\
iii & -1 & 1 & 0 \\
iv & 1 & 1 & 0 \\
$\mathbf{v}$ & -1 & 0 & -1 \\
vi & 1 & 0 & -1 \\
vii & -1 & 0 & 1 \\
viii & 1 & 0 & 1 \\
ix & 0 & -1 & -1 \\
x & 0 & 1 & -1 \\
xi & 0 & -1 & 1 \\
xii & 0 & 1 & 1 \\
xiii & 0 & 0 & 0 \\
xiv & 0 & 0 & 0 \\
xv & 0 & 0 & 0 \\
xvi & 0 & 0 & 0 \\
xvii & 0 & 0 & 0 \\
\hline
\end{tabular}

The experimental values obtained were then used to generate the response surface model. To design the response ( $\mathrm{z}$ ) as a function of three factors. The second order polynomial shown in Equation (3) is used.

$$
z=b_{0}+b_{1} P_{1}+b_{2} P_{2}+b_{3} P_{3}+b_{11} P_{1}^{2}+b_{22} P_{2}^{2}+b_{12} P_{1} P_{2}+b_{13} P_{1} P_{3}+b_{23} P_{2} P_{3}
$$

Analysis by means of regression was then applied using Design-Expert ${ }^{\circledR}$ analysis codes to determine the values for the coefficient. The equations used are as shown in Equations (4)-(7).

$$
\begin{gathered}
b_{o}=\overline{y_{0}} \\
b_{i}=A \sum_{U=1}^{N} X_{i u} y_{u} \\
b_{i i}=B \sum_{U=1}^{N} X_{i u}^{2} y_{u}+C_{1} \sum_{U=1}^{N} X_{i i}^{2} y-\left(\overline{y_{0} / s}\right) \\
b_{i j}=D_{1} \sum_{U=1}^{N} X_{i U} X_{j u} y_{U}
\end{gathered}
$$

where the number of experiments performed is represented by $\mathrm{N}$, the number of factors is also represented by I and the observations maintained at the centre point on average was A, B, C1 and D1, which is represented by yo. The three independent variables considered are equal to $1 / 8,1 / 4,-1 / 16$ and $\frac{1}{4}$ and sum of squares of each value for the BBD is shown in Equations (8)-(10).

$$
\begin{gathered}
S S_{b i}=A \sum_{U=1}^{N}\left(X_{i U} y_{2}\right)^{2} \\
S S_{b i j}=D_{i} \sum_{U=1}^{N}\left(X_{i U} X_{j u} y_{U}\right)^{2} \\
S S_{i i}=b_{o} \sum_{U=1}^{N} y_{U}+b_{i i} \sum_{U=1}^{N} X_{i U}^{2} y_{U}-\sum_{U=1}^{N}\left(y_{U}\right)^{2} / N
\end{gathered}
$$


The developed design was investigated by means of analysis of variance (ANOVA) captured in Table 2. Statistical importance for the model conceptualized as well as the specific constants and variables in the regression analysis were determined by means of the sequential F-test. This test depended on the Prob > F ( $p$-values) and these values were obtained using analysis of variance. Assuming that Prob $>\mathrm{F}$ for the numerical design for every value in the design does not go beyond the significance level of a (where $\mathrm{a}=0.05$ ), then the numerical design is described as adequate, falling in the boundaries of the confidence interval of $(1-$ Prob $>F)$. Some parameters like $R_{2}$, predicted $R_{2}$ and adequate precision ratio were carefully investigated specifically in analysis of variance to produce good results that was in perfect agreement with literature. Value for the $R_{2}$ can be used to determine the proportion of variability in a data set accounted for using the proposed model. The proportionality of the variables can be determined using the values for $R_{2}$ obtained from the numerical design proposed. The variability of the numerical design is defined as sum of squares and determined using Equations (11)-(13). An important modification of $R_{2}$ is the Adjusted $R_{2}$.

Table 2. ANOVA for the numerical design.

\begin{tabular}{|c|c|c|c|c|c|}
\hline Term & BB & Df & MB & $F_{c a l}-$ Value & $p$-Value or Prob $>F$ \\
\hline $\begin{array}{l}\text { Numerical } \\
\text { design }\end{array}$ & $B B_{M}$ & $\mathrm{P}$ & & & \\
\hline$P_{1}$ & $B B_{1}$ & 1 & & & \\
\hline$P_{2}$ & $B B_{2}$ & 1 & & & \\
\hline$P_{3}$ & $B B_{3}$ & 1 & Each BB & & \\
\hline$P_{1} P_{2}$ & $B B_{12}$ & 1 & divided by its' & divided by $\mathrm{MBr}$ & software library \\
\hline$P_{1} P_{3}$ & $B B_{13}$ & 1 & dff & & \\
\hline$P_{2} P_{3}$ & $B B_{23}$ & 1 & & & \\
\hline$P_{1}^{2}$ & $B B_{11}$ & 1 & & & \\
\hline$P_{2}^{\frac{1}{2}}$ & $B B_{22}$ & 1 & & & \\
\hline$P_{3}^{2}$ & $B B_{33}$ & 1 & & & \\
\hline Residual & $B B_{R}$ & $\mathrm{~N}-p-1$ & & & - \\
\hline Cor Total & $B B_{T}$ & $\mathrm{~N}-1$ & - & - & - \\
\hline
\end{tabular}

Sum of squares-model $=B B_{M}$

$$
\sum_{U=1}^{N}\left(\hat{C_{U}}-\bar{C}\right)^{2}
$$

Sum of squares-residuals $=B B_{R}$

$$
\sum_{U=1}^{N}\left(C_{U}-\hat{C_{U}}\right)^{2}
$$

Sum of square-total $=B B_{T}$

$$
\begin{gathered}
\sum_{U=1}^{N}\left(C_{U}-\bar{C}\right)^{2}=B B_{M}+B B_{R} \\
\text { R-squared }=R^{2}=\left[\frac{B B_{M}}{B B_{T}}\right]
\end{gathered}
$$

Adjusted R-squared

$$
\begin{gathered}
\text { AdjR } R^{2}=1-\left[\left(\frac{B B_{R}}{d f_{R}}\right) \times\left(\frac{B B_{T}}{\left(d f_{R}+d f_{M}\right)}\right]^{-1}\right. \\
\text { Predicted R-squared }=\text { Pred } R^{2}=1-\left[\frac{\text { PRESS }}{B B_{T}}\right] \\
\text { PRESS }=\sum_{U=1}^{N}\left(C_{U}-\hat{C_{u,-i}}\right)^{2}
\end{gathered}
$$


Adequate precision

$$
\text { Adeq. precision }=\frac{\operatorname{maximum}(\hat{C})-\operatorname{minimum}(\hat{C})}{\sqrt{\frac{P P \times M B_{R}}{n}}}
$$

where $C, \hat{C}$ : the data generated from the experiment; $P P$ : model coefficient in terms of number; $n$ : overall runs performed during experiment; no: Total centre points; dff: degree of freedom; $M B$ : Mean square; $\hat{C_{u,-i}}:$ Predicted output.

The numerical design is made up of less significant numerical constants $(\alpha)$ which is normally $p$-value higher than the value anticipated to be deleted. Stepwise regression elimination approach, backward deletion and forward eliminating approach are the well-known automatic ways of carrying out elimination in ANOVA. Others also prefer the manual approach. The elimination only results in numerical constants that are significant. It is important the terms are hierarchically kept constant. The numerical design was seen to be adequate after the model was properly checked in ANOVA. The response became easy to predict and this led to the generation of 3D contours, perturbation and interaction plots.

\section{Materials and Methods}

\subsection{Testing of Fuel Cell}

The fuel cell which has the serpentine flow plate design was purchased from a fuel cell store in the United States (US) with an active area of $11.46 \mathrm{~cm}^{2}$. One of the manufacturers specifications was to have the membrane humidified to prevent the possibility of it drying up. The PEM fuel cell was dismantled to examine how the various components interacted with each other in the cell, and to get an idea on the impact of the operating conditions likely to have on each layer in the stack. Figure 1 shows the dismantled view of the fuel cell. The cell was then tested using various parameters and analyzed through design of experiments. The experiment was performed considering the impact that three experimental conditions will have on the output for a PEMFC. The various conditions were also optimized to determine the best operating conditions to achieve the maximum voltage and current. Several graphs were generated through DOE in response to these operating parameters. The air pressure was initially set to be below the hydrogen pressure but from the manufacturers' specification, the oxygen had to be supplied in large quantities as captured in Table 3.

Table 3. Fuel cell experimental parameters.

\begin{tabular}{cccc}
\hline Level of Numerical Design & $\mathbf{- 1}$ & $\mathbf{0}$ & $\mathbf{+ 1}$ \\
\hline Input variable level & First experiment & Second experiment & Third experiment \\
$\mathrm{H}_{2}$ pressure & $1 \mathrm{bar}$ & $1.75 \mathrm{bar}$ & $2.5 \mathrm{bar}$ \\
$\mathrm{O}_{2}$ pressure & $0.8 \mathrm{bar}$ & $1.55 \mathrm{bar}$ & $2.3 \mathrm{bar}$ \\
$\mathrm{H}_{2}$ velocities & $15 \mathrm{~mL} / \mathrm{min}$ & $82.5 \mathrm{~mL} / \mathrm{min}$ & $150 \mathrm{~mL} / \mathrm{min}$ \\
$\mathrm{O}_{2}$ velocities & $15 \mathrm{~mL} / \mathrm{min}$ & $82.5 \mathrm{~mL} / \mathrm{min}$ & $150 \mathrm{~mL} / \mathrm{min}$ \\
\hline
\end{tabular}

\subsection{Experimental Set Up}

The experimental set up is as shown in Figure 4. The hydrogen gas was produced using a hydrogen generator from Peak Instrument, UK, where the reacting oxygen was obtained by directing air through the air vents of the fuel cell with the aid of a fan. The pressure of the hydrogen fuel was varied between 1 and 2.5 bar. The fuel (hydrogen) was then directed through a flow meter to determine the velocity of the gas before entering the fuel cell. Once the gas velocity was determined, the hydrogen was then passed through a humidified chamber before finally entering the anode region of the fuel cell. The working environment for the experiment had a relative humidity of 0.74 and the air flow rate was also determined from the data sheet of the fan used in the experiment. A potentiostat from Gamry 
Instrument was used to generate the polarization curve at each working condition. The open circuit voltage and current was also determined using a multi meter. A thermocouple was attached to the fuel cell to determine the cell operating temperature at varying operating condition as shown in Figure 4. The bipolar plate geometry used in the entire investigation is also shown in Figure 4 . The fuel cell was operated at temperatures in the range of $50-60^{\circ} \mathrm{C}$.

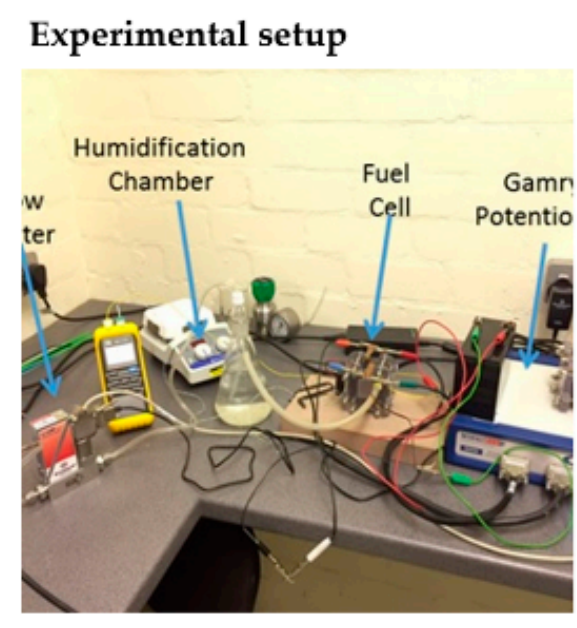

\section{Parallel design}

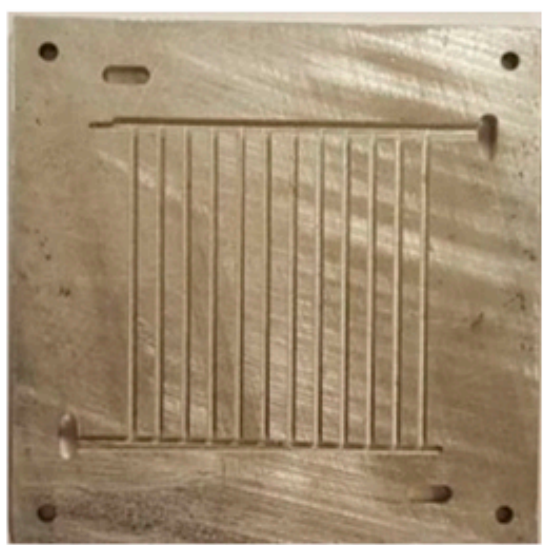

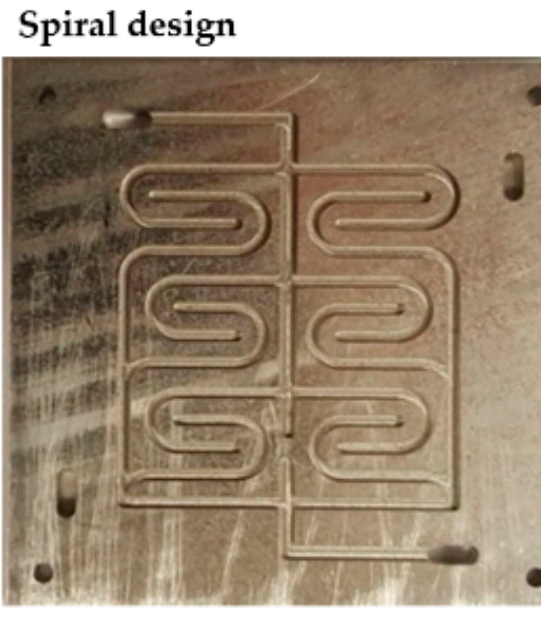

Interdigitated

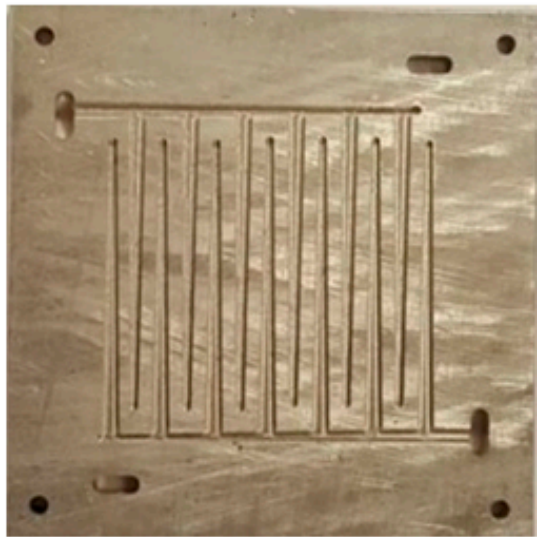

Figure 4. Experimental set up for the testing of the fuel cell with varying flow-plate geometries.

\subsection{Measured Responses}

One of the measured responses from the experiment was the voltage (V). According to Ohm's law, potential difference $(\mathrm{V})$ is directly proportional to current and this is dependent on the resistance, as shown in Equation (19).

$$
V=I \times R
$$

where $V=$ potential difference of the circuit, $I$ current obtained from the cell and $R$ is the opposition to the flow of current in the circuit (resistance).

Potential (V) for PEMFCs is slightly different from other circuit designs. The electrical energy performance as well as the voltage between the anodic and cathodic region at maximum conditions is obtained when the fuel cell is being tested under thermodynamically reversible conditions. At any current density, subtracting the irreversible potential from the reversible potential gives the net output voltage of the fuel cell as shown in Equation (20).

$$
V(i)=V_{\text {rev }}-V_{\text {irrev }}
$$


From Equation (20), $V_{\text {rev }}=E_{r}$ : the overall output (reversible) potential of the cell and $V_{\text {irrev }}$ : irreversible potential loss (overpotential) around the PEMFC but

$$
\begin{gathered}
V_{\text {irrev }}=v_{\text {act }}+v_{\text {ohmic }}+v_{\text {conc }} \\
V(i)=E_{r}-\left(v_{\text {act }}+v_{\text {ohmic }}+v_{\text {conc }}\right)
\end{gathered}
$$

It must also be noted that fuel cell performance is often determined using the polarization curve. The current as well as voltage are determined from the experiment conducted using the PEMFC and polarization curve (current against voltage). The cell under normal circumstance will produce current as long as the reactants are being supplied to it, but the voltage remains constant. The electrical efficiency is often determined from the open circuit voltage. When the open circuit voltage is low, the electrical efficiency is also low. A product of the voltage and current gives the power shown in Equation (23).

$$
P=I \times V
$$

Membrane electrode assemblies (MEA) are categorized depending on their active area. This is performed by dividing the obtained power and current by active area of the cell stack. Polarization curves were drawn for each of the conditions. The point of interception on the polarization curve that exhibits a perfect correlation between high voltage and the overall power density was also reported. Maximum voltage efficiency for all the design considered were also presented in this article. The overall voltage obtained when the fuel cell is not producing any current or, in other words, the open circuit voltage (OPCV), divided by the maximum potential of $1.23 \mathrm{~V}$ theoretically, gives the voltage efficiency as shown in Equation (24).

$$
\varepsilon_{\text {voltage }}=V_{\text {measured }} / V_{\text {theoretical }}
$$

The hydrogen gas $\left(\mathrm{H}_{2}\right)$ that goes into reaction with respect to time expressed as a percentage gives the fuel efficiency. The inefficiencies in PEMFC as well as the unstable gas velocity as they flow through the various layers of the cell often makes the efficiency low. It can also be determined using the input velocity of the $\mathrm{H}_{2}$ in relation to current generated from the cell stack using Equation (25)

$$
\varepsilon_{f u e l}=\frac{\left(\frac{I}{n F}\right)}{v_{f u e l}}
$$

I represents the currents obtained during the experimental process and $\mathrm{n} \times \mathrm{F}$, is maintained as a constant $(2 \times 96,485)$ and this is applicable to all experiments conducted. The pace at which the $\mathrm{H}_{2}$ flows into the cell stack is represented by $v_{f u e l}$. There is variation of this fuel speed with respect to the three types of gas velocities expressed as flow rates under investigation. An example is representing the velocity of the gas in terms of flow rate as $82.5 \mathrm{~mL} / \mathrm{min}$ in $\mathrm{mol} / \mathrm{second}$,

$$
82.5 \mathrm{~mL} / \mathrm{min}=0.001375 \mathrm{~L} / \mathrm{s} \text { or } 1.375 \times 10^{-6}
$$

Mole is expressed in unit of mass quite often hence the flow rate is obtained as $\mathrm{m} / \mathrm{s}$, where $\mathrm{m}$ is mass and s is seconds. A multiplication of hydrogen density which is $0.08988 \mathrm{~g} / \mathrm{L}$ (g: grams L: litres) and the flow rate was then performed. The result generated showed that $0.000124 \mathrm{~g}$ of $\mathrm{H}_{2}$ goes into reaction every second at that specific flow rate. $\mathrm{H}_{2}$. Dividing this result by two gives the molecular weight because a covalent bond is shared between two hydrogen molecules. It shows that the pace at which $\mathrm{H}_{2}$ is introduced into the flow channels of the PEMFC is $0.00006179 \mathrm{~mol} / \mathrm{s}$. PEMFC efficiency is also determined using higher heating value for the fuel (hydrogen) as shown in Equations (27) and (28) also shows an alternative for determining the efficiency of the PEMFC.

$$
\eta=I V / v_{f u e l} H^{O}
$$


where $H^{O}$ is the higher heating value

$$
\eta=\varepsilon_{\text {voltage }} \times \varepsilon_{f u e l}
$$

\section{Results}

Design of experiment (DOE) is used to analyze each experiment to predict the accuracy and possibilities of errors during the performance of the experiment. The number of runs for the experiment is listed randomly and this guarded against some specific constants like time, temperature, humidity, etc. Several factors were considered in order to determine if the values in the numerical design needs transformation. Some of the common transformation techniques used are $\operatorname{logs} z^{\prime}=\ln (z+a)$ and the square roots $z^{\prime}=\operatorname{sqrt}(z+a)$. For instance, where the ratio of the maximum and minimum set of data point exceeds 10, transformation is often recommended. This is done by means of a click of an icon which is the diagnostic tag and then choosing the box-Cox option only when required. Transformation usually makes the results skewed and so it is best to leave the results in their original states. Table 4 shows the measured responses for the current and voltage at different operating conditions.

Table 4. Measured experimental data.

\begin{tabular}{|c|c|c|c|c|c|c|c|}
\hline & & Factor 1 & Factor 2 & Factor 3 & Factor 4 & Response 1 & Response 2 \\
\hline Std & Run & $\begin{array}{c}\text { A: Hydrogen } \\
\text { Pressure }\end{array}$ & $\begin{array}{l}\text { B: Oxygen } \\
\text { Pressure }\end{array}$ & $\begin{array}{l}\text { C: Hydrogen } \\
\text { Flow Rate }\end{array}$ & $\begin{array}{l}\text { D: Oxygen } \\
\text { Flow Rate }\end{array}$ & Current & Voltage \\
\hline & & bar & bar & $\mathrm{mL} / \mathrm{min}$ & $\mathrm{mL} / \mathrm{min}$ & A & V \\
\hline 1 & 1 & 1 & 0.8 & 82.5 & 82.5 & 3.8 & 4.6 \\
\hline 3 & 2 & 1 & 2.3 & 82.5 & 82.5 & 3.51 & 4.55 \\
\hline 7 & 3 & 1.75 & 1.55 & 15 & 150 & 3.86 & 4.64 \\
\hline 17 & 4 & 1 & 1.55 & 15 & 82.5 & 3.88 & 4.71 \\
\hline 23 & 5 & 1.75 & 0.8 & 82.5 & 150 & 3.74 & 4.69 \\
\hline 13 & 6 & 1.75 & 0.8 & 15 & 82.5 & 3.91 & 4.74 \\
\hline 6 & 7 & 1.75 & 1.55 & 150 & 15 & 3.58 & 4.57 \\
\hline 5 & 8 & 1.75 & 1.55 & 15 & 15 & 3.49 & 4.4 \\
\hline 10 & 9 & 2.5 & 1.55 & 82.5 & 15 & 3.47 & 4.39 \\
\hline 12 & 10 & 2.5 & 1.55 & 82.5 & 150 & 3.8 & 4.61 \\
\hline 16 & 11 & 1.75 & 2.3 & 150 & 82.5 & 3.95 & 4.8 \\
\hline 20 & 12 & 2.5 & 1.55 & 150 & 82.5 & 3.79 & 4.71 \\
\hline 28 & 13 & 1.75 & 1.55 & 82.5 & 82.5 & 3.65 & 4.50 \\
\hline 25 & 14 & 1.75 & 1.55 & 82.5 & 82.5 & 3.67 & 4.54 \\
\hline 9 & 15 & 1 & 1.55 & 82.5 & 15 & 3.49 & 4.38 \\
\hline 8 & 16 & 1.75 & 1.55 & 150 & 150 & 3.83 & 4.64 \\
\hline 27 & 17 & 1.75 & 1.55 & 82.5 & 82.5 & 3.77 & 4.79 \\
\hline 24 & 18 & 1.75 & 2.3 & 82.5 & 150 & 3.81 & 4.68 \\
\hline 15 & 19 & 1.75 & 0.8 & 150 & 82.5 & 3.73 & 4.65 \\
\hline 26 & 20 & 1.75 & 1.55 & 82.5 & 82.5 & 3.61 & 4.55 \\
\hline 19 & 21 & 1 & 1.55 & 150 & 82.5 & 3.78 & 4.68 \\
\hline 18 & 22 & 2.5 & 1.55 & 15 & 82.5 & 3.76 & 4.67 \\
\hline 22 & 23 & 1.75 & 2.3 & 82.5 & 15 & 3.64 & 4.55 \\
\hline 14 & 24 & 1.75 & 2.3 & 15 & 82.5 & 3.95 & 4.92 \\
\hline 29 & 25 & 1.75 & 1.55 & 82.5 & 82.5 & 3.66 & 4.66 \\
\hline 2 & 26 & 2.5 & 0.8 & 82.5 & 82.5 & 3.69 & 4.69 \\
\hline 21 & 27 & 1.75 & 0.8 & 82.5 & 15 & 3.61 & 4.67 \\
\hline 4 & 28 & 2.5 & 2.3 & 82.5 & 82.5 & 3.9 & 4.89 \\
\hline 11 & 29 & 1 & 1.55 & 82.5 & 150 & 3.65 & 4.54 \\
\hline
\end{tabular}

\subsection{Voltage}

At the maximum operating conditions, the normality plot is shown in Figure 5. The normal plot in diagnostics as shown in Figure 5 below is used to determine whether the results are normally distributed. Under normal circumstances, the plot depicting the residual should be a linear showing no abnormalities. From the normality plot, there is linearity between the experimental set points. 


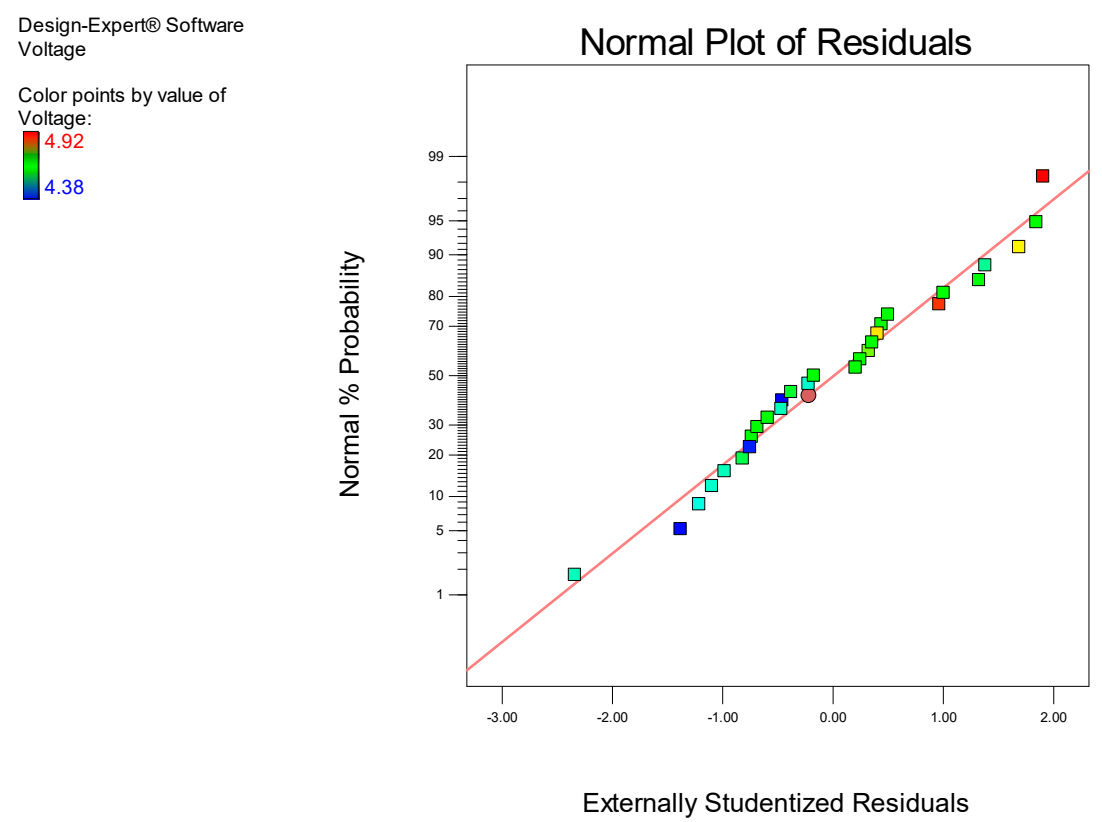

Figure 5. Normality plot at the maximum operating conditions.

Analysis of Variance (ANOVA) for the Voltage

From the ANOVA results tabulated in Table 5, the F-value being 11.04 represents the fact that the numerical design is significant and only 0.01 percent possibility that an F-value this big can occur because of noise. Again, the data points of the Prob > F is far below 0.0500, depicting the fact that the numerical design terms are significant. This implies that $\mathrm{D}, \mathrm{AB}, \mathrm{B}^{2}, \ldots, \mathrm{D}^{2}$ are significant. The ANOVA shows that the following parameters were significant in terms of the voltage analysis.

1. The first order effect of hydrogen pressure (A), oxygen pressure (B), hydrogen flow rate (C) and oxygen flow rate $(\mathrm{D})$.

2. The second order effect of $A^{2}, B^{2}, C^{2}, D^{2}$.

3. The two mode of interaction between hydrogen pressure $(A)$ as well as oxygen flow rate $(A \times D)$, oxygen pressure $(B)$ and hydrogen flow rate $(B \times C)$.

Table 5. Analysis of variance response surface numerical design for voltage for spiral flow channel.

\begin{tabular}{|c|c|c|c|c|c|c|}
\hline Term & $B B_{m}$ & Df & MB & F-Value & $\begin{array}{l}p \text {-Value } \\
\text { Prob > F }\end{array}$ & \\
\hline Numerical design & 0.266 & 6 & 0.044 & 4.72 & 0.0031 & \multirow[t]{10}{*}{ significant } \\
\hline A-Hydrogen pressure & 0.021 & 1 & 0.021 & 2.23 & 0.1497 & \\
\hline B-Oxygen pressure & 0.010 & 1 & 0.010 & 1.09 & 0.3074 & \\
\hline $\mathrm{C}-$ Hydrogen flow rate & $7.500 \times 10^{-5}$ & 1 & $7.500 \times 10^{-5}$ & $8.023 \times 10^{-3}$ & 0.9294 & \\
\hline $\mathrm{D}$-Oxygen flow rate & 0.059 & 1 & 0.059 & 6.29 & 0.0200 & \\
\hline $\mathrm{AB}$ & 0.067 & 1 & 0.067 & 7.17 & 0.0137 & \\
\hline $\mathrm{B}^{2}$ & 0.084 & 1 & 0.084 & \multirow[t]{4}{*}{8.97} & 0.0067 & \\
\hline$C^{2}$ & 0.096 & 1 & 0.096 & & 0.0003 & \\
\hline $\mathrm{D}^{2}$ & 0.036 & 1 & 0.036 & & 0.0148 & \\
\hline Residual & 0.21 & 22 & $9.349 \times 10^{-3}$ & & & \\
\hline Lack of fit & 0.16 & 18 & $8.664 \times 10^{-3}$ & \multirow[t]{4}{*}{0.70} & 0.7369 & \multirow[t]{4}{*}{$\begin{array}{c}\text { not } \\
\text { significant }\end{array}$} \\
\hline Pure Error & 0.050 & 4 & 0.012 & & & \\
\hline Cor Total & 0.47 & 28 & & & & \\
\hline $\mathrm{R}^{2}=0.8154$ & $\begin{array}{l}\text { Predicted } \mathrm{R}^{2} \\
\quad=0.8154\end{array}$ & $\begin{array}{c}\operatorname{Adj} R^{2}= \\
0.7416\end{array}$ & $\begin{array}{c}\text { Adequate } \\
\text { precision }= \\
12.015\end{array}$ & & & \\
\hline
\end{tabular}


The same approach was used for all the three bipolar plate designs which showed that the interdigitated had the least voltage among the other designs at the maximum operating pressure conditions. The interdigitated design yielded a voltage of $3.46 \mathrm{~V}$ at the maximum pressure and that of the parallel design yielded a voltage of $4.1 \mathrm{~V}$ at the maximum operating conditions. The spiral flow plate gave the best results. The results obtain showed an increase in voltage for the spiral design from 1 bar $(3.96 \mathrm{~V})$ to 2.5 bar $(4.9 \mathrm{~V})$, as shown in Figure 6

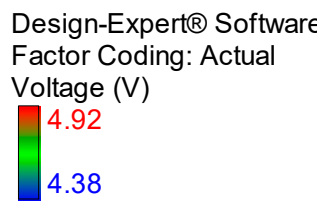

$\mathrm{X} 1=\mathrm{A}:$ Hydrogen pressure $\mathrm{X} 2=\mathrm{B}$ : Oxygen pressure

Actual Factors

C: Hydrogen flow rate $=15$

D: Oxygen flow rate $=100.743$

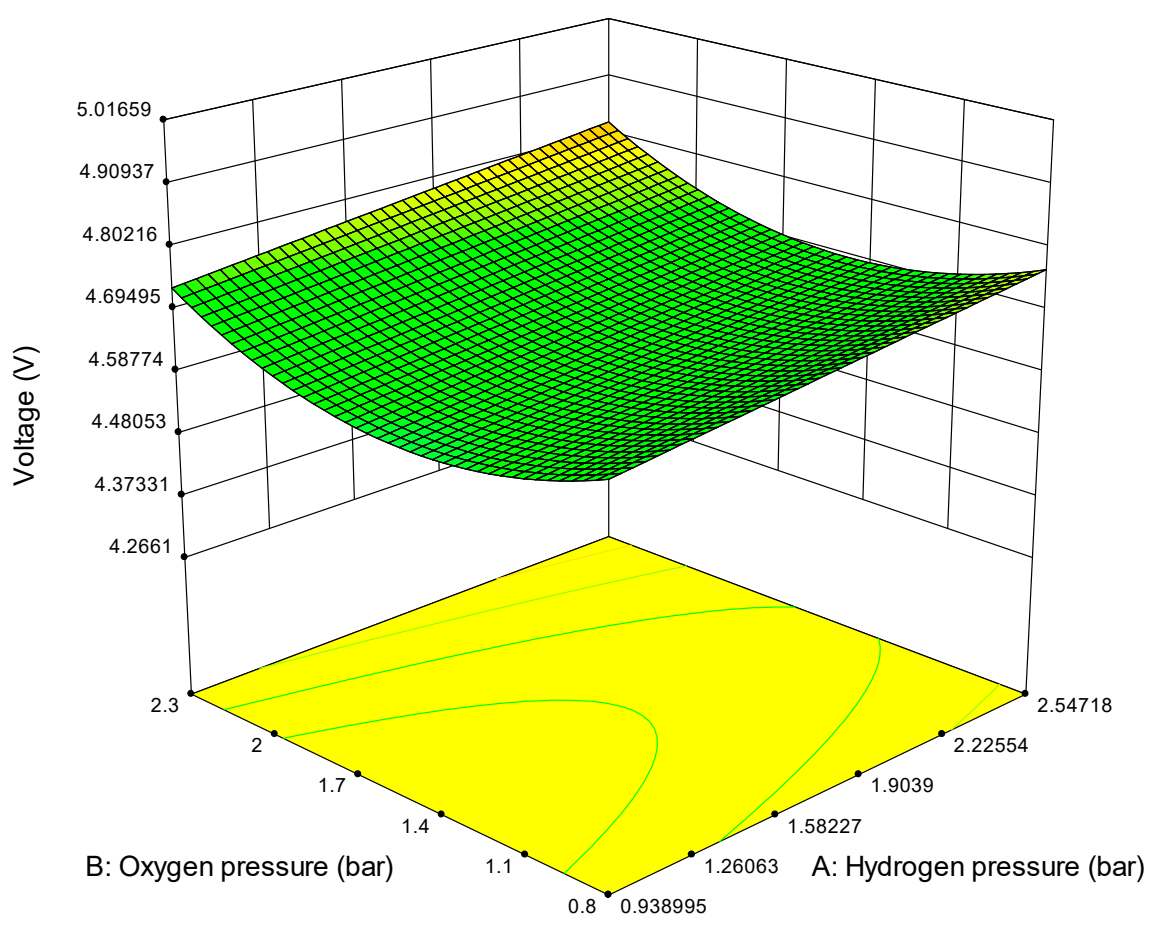

Figure 6. Overall voltage for the spiral flow channel at maximum cell operating pressure.

A vivid explanation to this is that increasing the oxygen flow rate at a reduced hydrogen flow rate will still make the spiral bipolar plate fuel cell perform better and this condition is applicable to the parallel design and the interdigitated design, except that the voltage obtained from this designs are low. Again, for all the pressures and flow rates used in the experiment, the maximum voltage efficiency obtained was from the spiral design and this was done with respect to the highest theoretical voltage at open circuit voltage. The spiral design generated the best results as shown in Figure 7a. The maximum efficiency obtained for the spiral flow channel was the highest for the flow rates and pressures used during the analysis. The spiral flow plate design gave a voltage efficiency of $85.6 \%$ for lower velocities of the $\mathrm{H}_{2}$ and high $\mathrm{O}_{2}$ / Air velocities at maximum operating pressures. The parallel design gave a maximum voltage efficiency of $77.5 \%$ (Figure $7 \mathrm{~b}$ ), while the interdigitated design gave a maximum voltage efficiency of $75.5 \%$. 
a

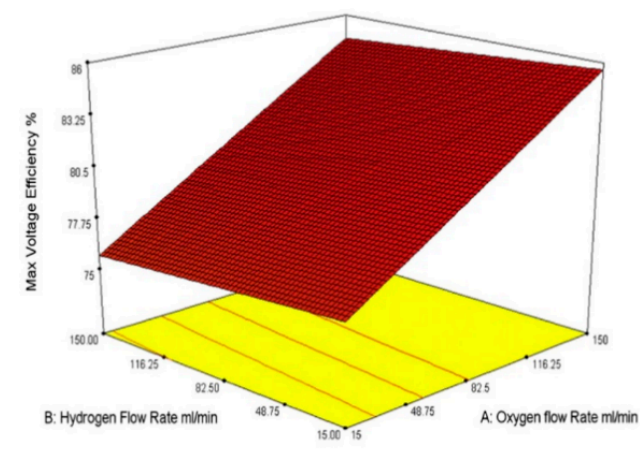

b

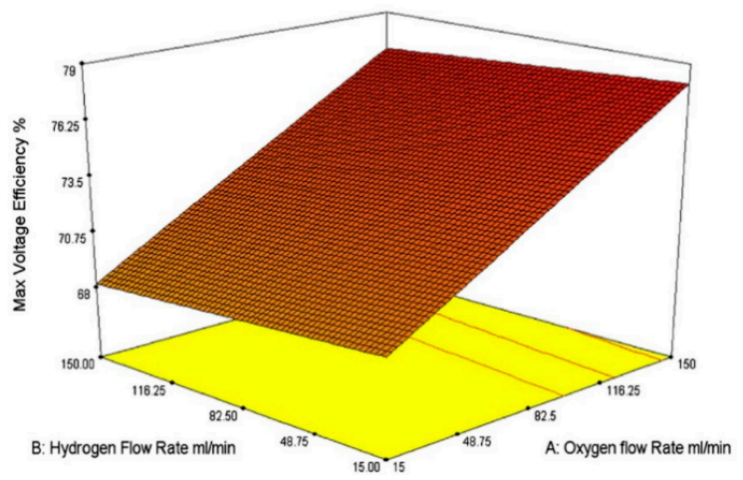

Figure 7. Maximum voltage efficiency for the (a) spiral design (b) parallel design.

\subsection{Current}

The current obtained for all the three (3) designs was not subject to increasing the operational pressure of the reactive gases. Increasing the pressure led to an increase from $2.4(1 \mathrm{bar})$ to $4.5 \mathrm{~A}$ at a maximum pressure of $2.5 \mathrm{bar}$ for the spiral design. The maximum current for all the designs were obtained at high oxygen and hydrogen flow rates. It is still possible to achieve high current at less hydrogen flow rate but more oxygen flow rate for the spiral design. From the analysis made in the design of the experiment, the highest current of $4.5 \mathrm{~A}$ was achieved by an increment in the oxygen velocity $(150 \mathrm{~mL} / \mathrm{min})$ and a rise the hydrogen velocity $(150 \mathrm{~mL} / \mathrm{min})$, as shown in Figure 8 a. Table 6 contains information about the analysis of variance response for current for the spiral design. The current does not experience any appreciable increase due to changes in velocities or flow rates. This implies that not all the hydrogen supplied go into reaction. This exposes the fact that for the fuel supplied to the fuel cell to produce more current, other components in the fuel cell like the membrane and catalyst layer must be optimized. The interdigitated channel shown in Figure 8c also exhibited an increase in the current as the oxygen and hydrogen flow rates increased. The obtained current of $4.2 \mathrm{~A}$ for the parallel channel plate shown in Figure $8 \mathrm{~b}$ was also due to an increase in the flow rates of the hydrogen and oxygen.
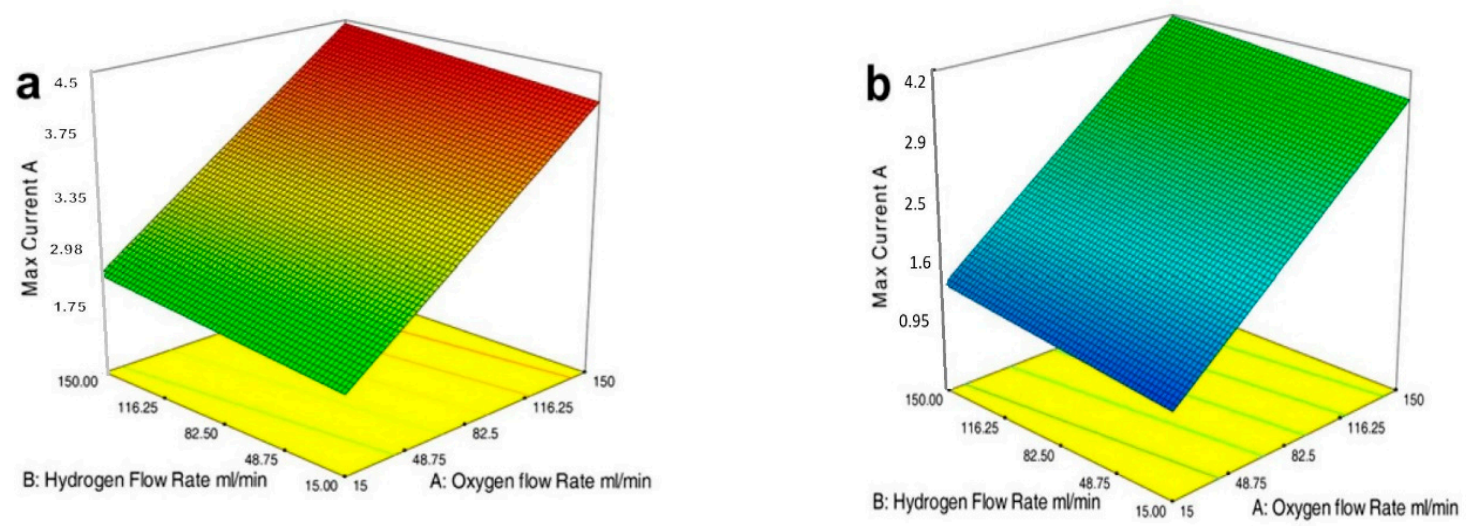

Figure 8. Cont. 


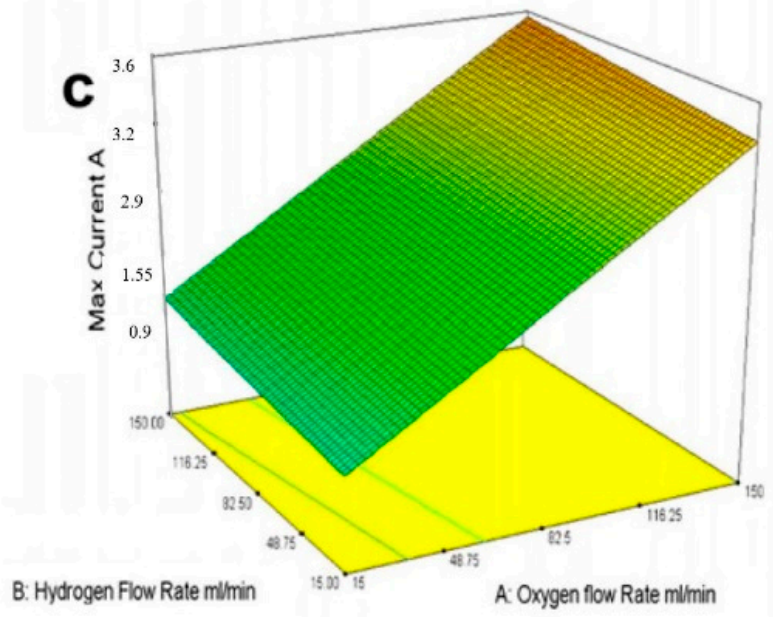

Figure 8. Maximum current generated for the three designs under investigation (a) Spiral (b) parallel (c) Interdigitated design.

Table 6. Analysis of variance response surface numerical design for current for spiral flow channel.

\begin{tabular}{clllll}
\hline Term & $\boldsymbol{B B}_{\boldsymbol{m}}$ & Df & MB & F-Value & $\begin{array}{l}\boldsymbol{p} \text {-Value } \\
\text { Prob }>\text { F }\end{array}$ \\
\hline Numerical design & 0.44 & 8 & 0.056 & 11.05 & $<0.0001$ \\
A-Hydrogen pressure & $7.500 \times 10^{-3}$ & 1 & $7.500 \times 10^{-3}$ & 1.49 & 0.2361 \\
B-Oxygen pressure & $6.533 \times 10^{-3}$ & 1 & $6.533 \times 10^{-3}$ & 1.30 & 0.2678 \\
C-Hydrogen flow rate & $3.008 \times 10^{-3}$ & 1 & $3.008 \times 10^{-3}$ & 0.60 & 0.4482 \\
D-Oxygen flow rate & 0.17 & 1 & 0.17 & 32.96 & $<0.0001$ \\
AB & 0.062 & 1 & 0.062 & 12.43 & 0.00021 \\
$\mathrm{~B}^{2}$ & 0.050 & 1 & 0.050 & 9.85 & 0.0052 \\
$\mathrm{C}^{2}$ & 0.096 & 1 & 0.096 & 19.13 & 0.0003 \\
$\mathrm{D}^{2}$ & 0.036 & 1 & 0.036 & 7.12 & 0.0148 \\
Residual & 0.10 & 20 & $5.027 \times 10^{-3}$ & & 0.3658 \\
Lack of fit & 0.086 & 16 & $5.404 \times 10^{-3}$ & 1.54 & not \\
Pure Error & 0.014 & 4 & $3.529 \times 10^{-3}$ & & significant \\
Cor Total & 0.54 & 28 & & & \\
$\mathrm{R}^{2}=0.8154$ & Predicted $\mathrm{R}^{2}=$ & Adj $\mathrm{R}^{2}=0.7416$ & precision $=$ & & \\
\end{tabular}

\subsection{Generated Power at Intercept}

The area/region on the plot that shows a perfect agreement between maximum cell potential and maximum power density is the intercept. The power obtained from the fuel cell according to the design of experiment investigation increased as the fuel and oxygen flow rates increased to nearly $21 \mathrm{~W}$ for a 5 -cell stack fuel cell at an operating temperature of $60^{\circ} \mathrm{C}$, as shown in Figure 9a. The parallel design generated power of $12.96 \mathrm{~W}$ at the maximum operating conditions for the 5-cell stack (Figure 9b), while the interdigitated gave 17.22 W (Figure 9c). For all the designs investigated, running the fuel cell from the lower operating conditions (pressure and flow rates) to higher operating conditions caused a marginal increase in the overall characteristic performance of the cell stack. 
a

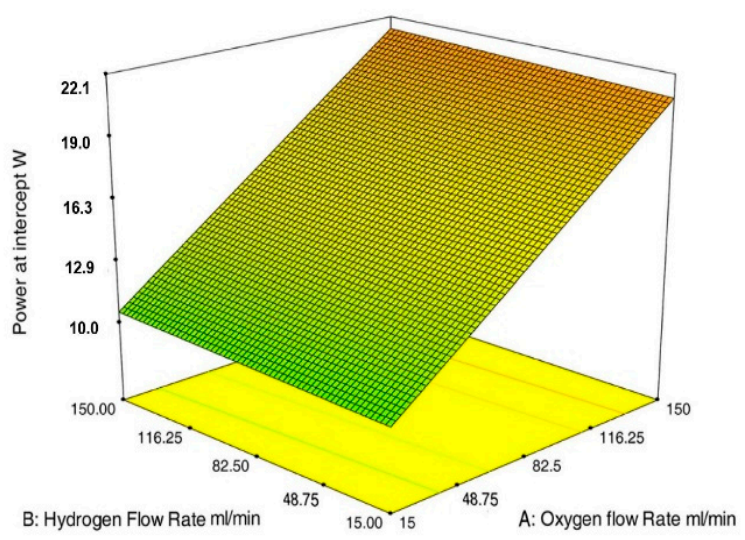

b

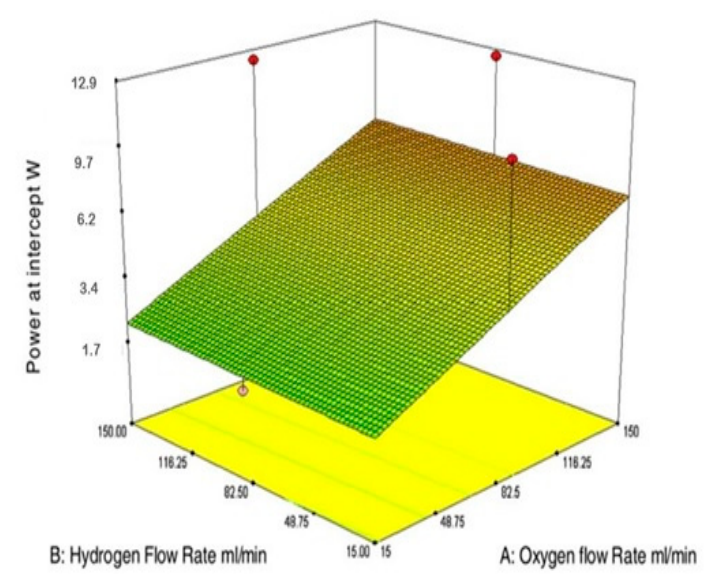

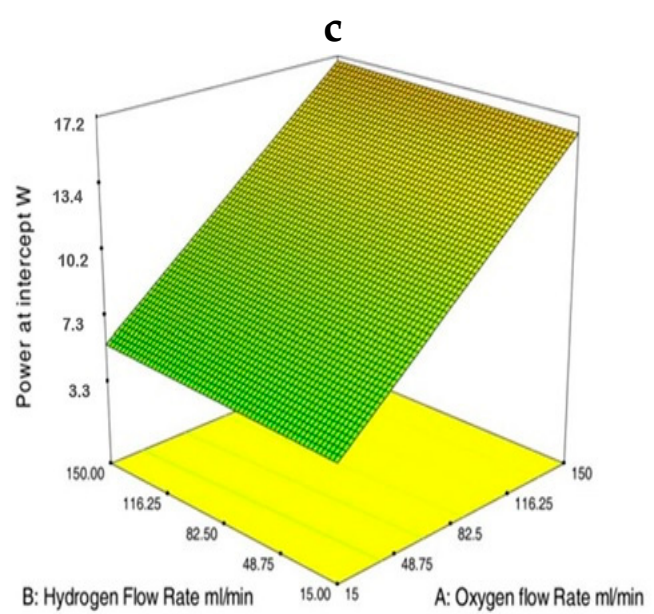

Figure 9. Power at intercept of polarization curve for the (a) spiral design (b) Parallel (c) Interdigitated design at maximum flow rates and pressure.

\subsection{Hydrogen (Fuel Efficiency)}

The fuel cell performance is usually determined using a quadratic plot. The efficiency of the hydrogen tends to increase for the spiral design at lower flow rates as well as pressures. The fuel efficiency increased with respect to a rise in oxygen gas velocity. From the plot in Figure 10a, it is possible to achieve a fuel efficiency of $29.6 \%$ at low pressures and low flow rates of hydrogen (15 $\mathrm{mL} / \mathrm{min}$ ) but medium flow rates of oxygen. The parallel design generates fuel efficiency of nearly $24.8 \%$ at low pressure and low- $\mathrm{H}_{2}$ velocities/flow rates and medium oxygen velocities of $110 \mathrm{~mL} / \mathrm{min}$ (Figure 10b). The hydrogen fuel efficiency for the interdigitated design is shown in Figure 10c.

The desirability for all the operating parameters was nearly one, as shown in Figure 11a. There were also several operating conditions that were varied to achieve the maximum current and voltage from the fuel cell for all the three designs, but the same analogy was constant for all three flow plate designs under investigations. Increasing the oxygen flow rate at a reduced current was a key determiner in attaining maximum current and voltage, as shown in Figure 11b. 
a

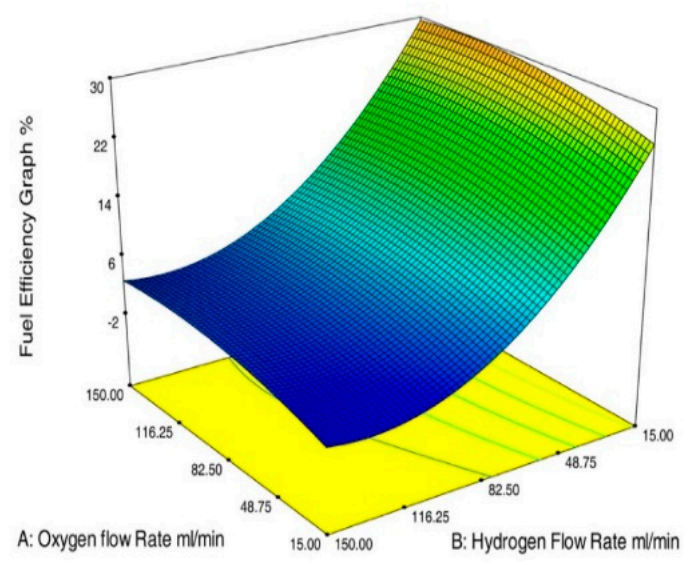

b

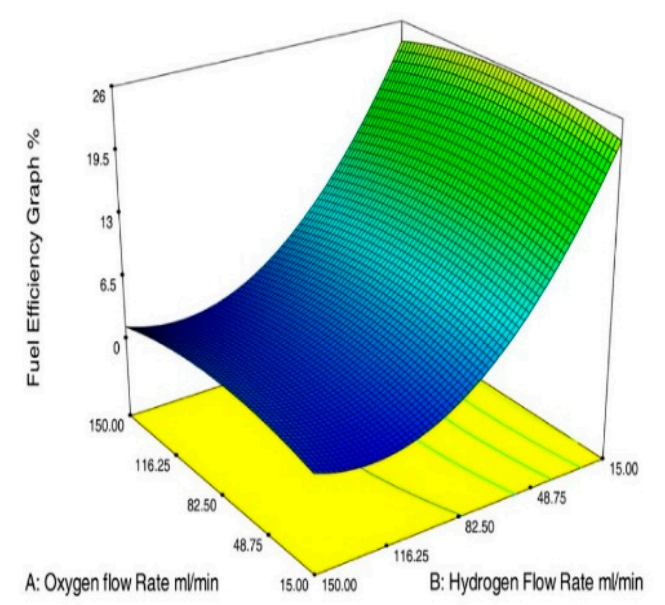

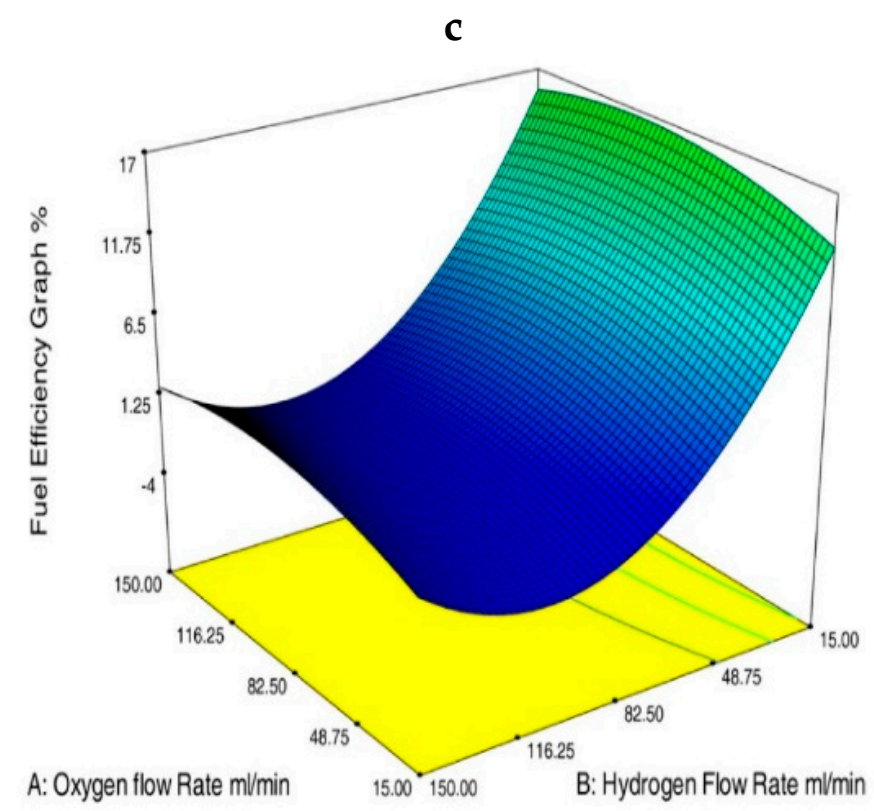

Figure 10. The fuel cell efficiency for the (a) spiral design (b) Interdigitated (c) Parallel design at medium cell operating conditions.

The best approach to cut down the cost needed in running the PEMFC is to know the exact operating region that would yield the maximum desired output from the fuel cell. This was performed using DOE as shown in Figure 12a. The yellow regions indicate the area that would produce the maximum performance from the fuel cell at specific operating conditions for the parallel design. Figure $12 \mathrm{~b}$ also shows the interaction of some operating conditions and the maximum current obtainable from these parameters using the spiral design as the flow channel. 
a

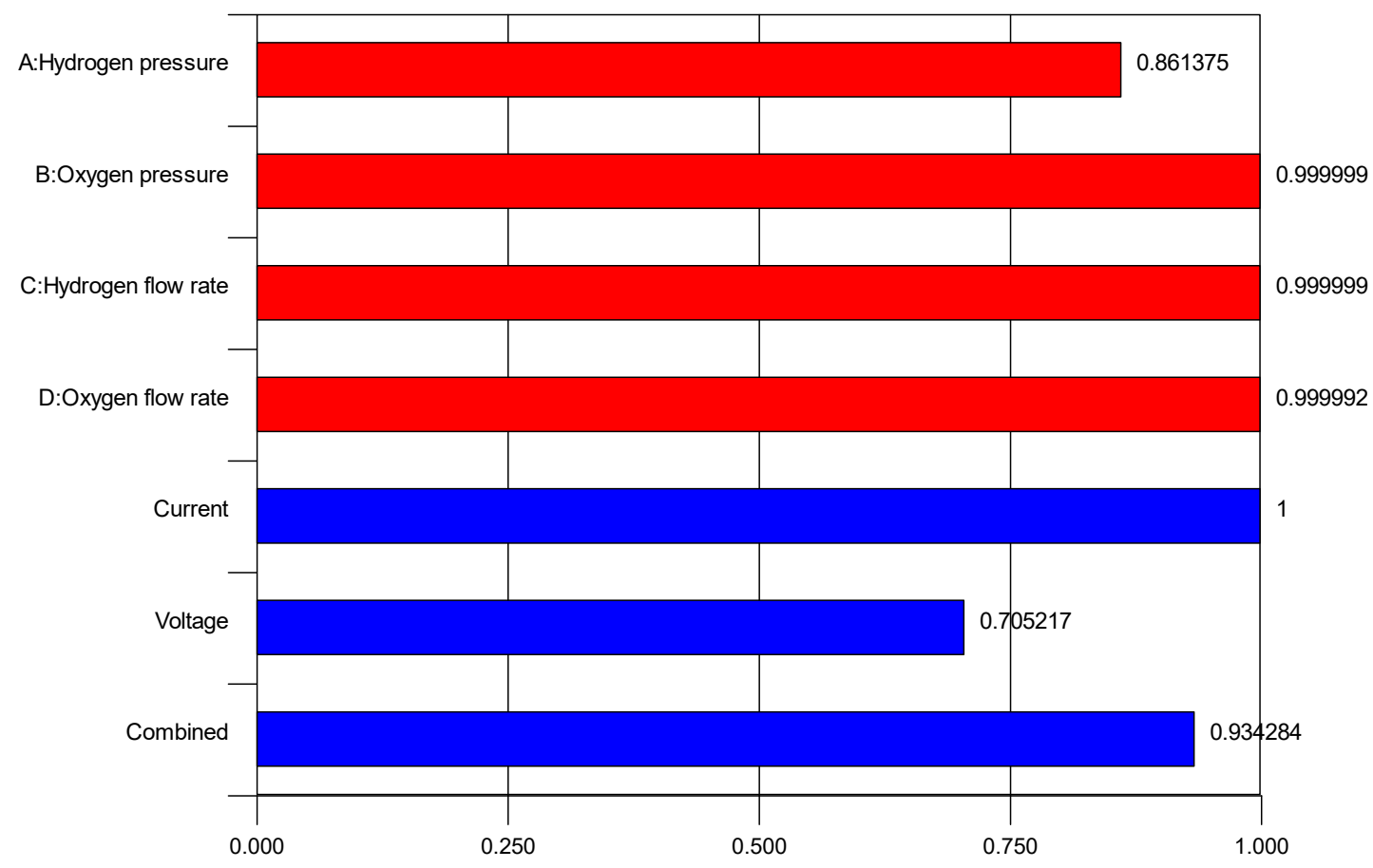

b
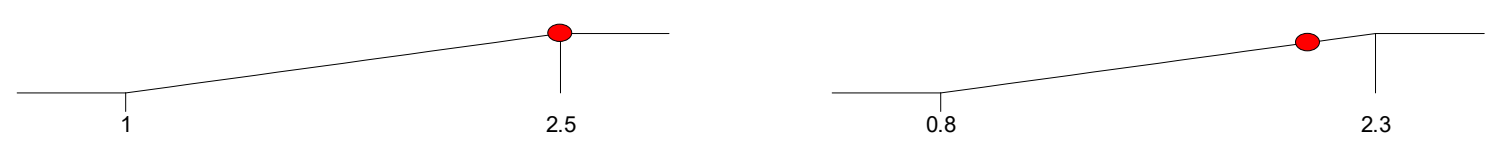

A:Hydrogen pressure $=2.5$

B: Oxygen pressure $=2.06775$
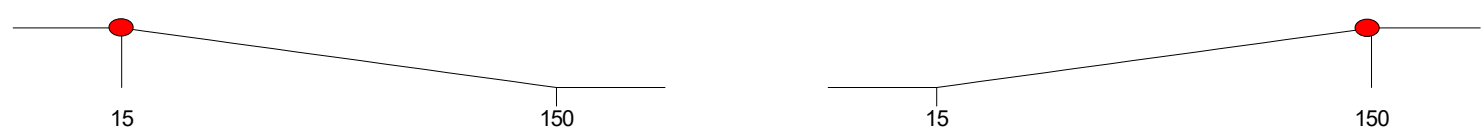

C: Hydrogen flow rate $=15.0033$

D:Oxygen flow rate $=148.853$
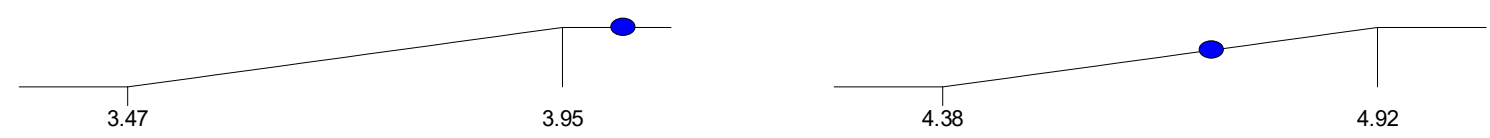

Current $=4.01735$

Voltage $=4.71427$

Desirability $=0.914$

Figure 11. (a) Model desirability for all the operating conditions (b) Varying the operational parameters to obtain the maximum performance from the fuel cell. 
a

Design-Expert@ Software
Factor Coding: Actual
Overlay Plot
Current
Voltage
X1 = C: Hydrogen flow rate
X2 = D: Oxygen flow rate
Actual Factors
A: Hydrogen pressure $=2.49999$
B: Oxygen pressure $=2.25739$

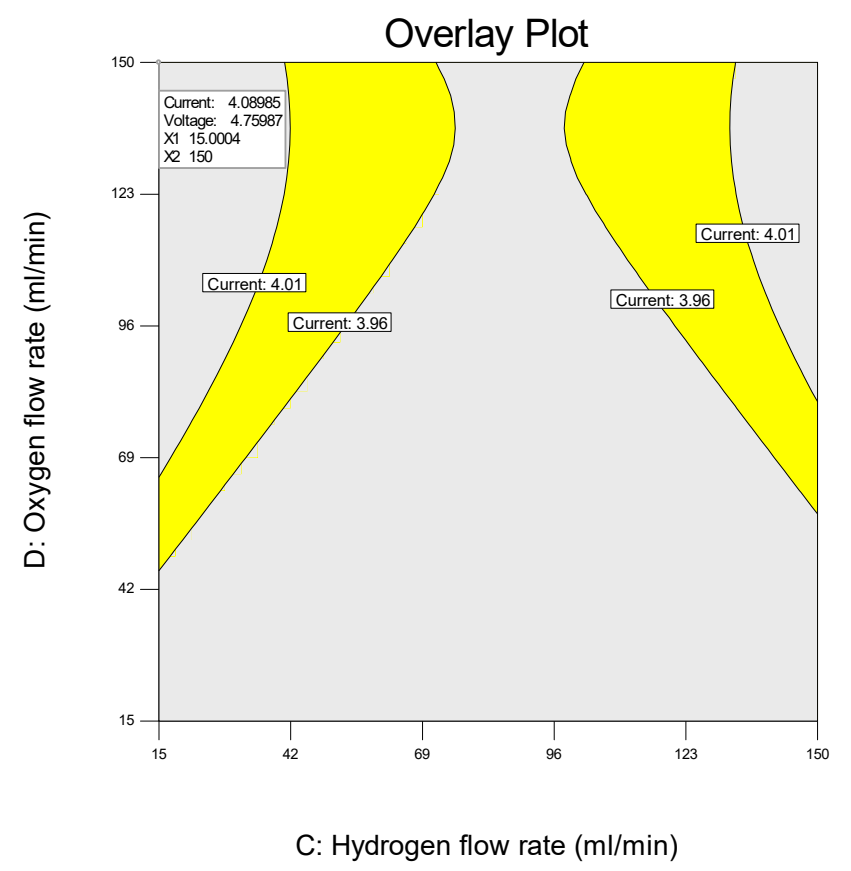

b

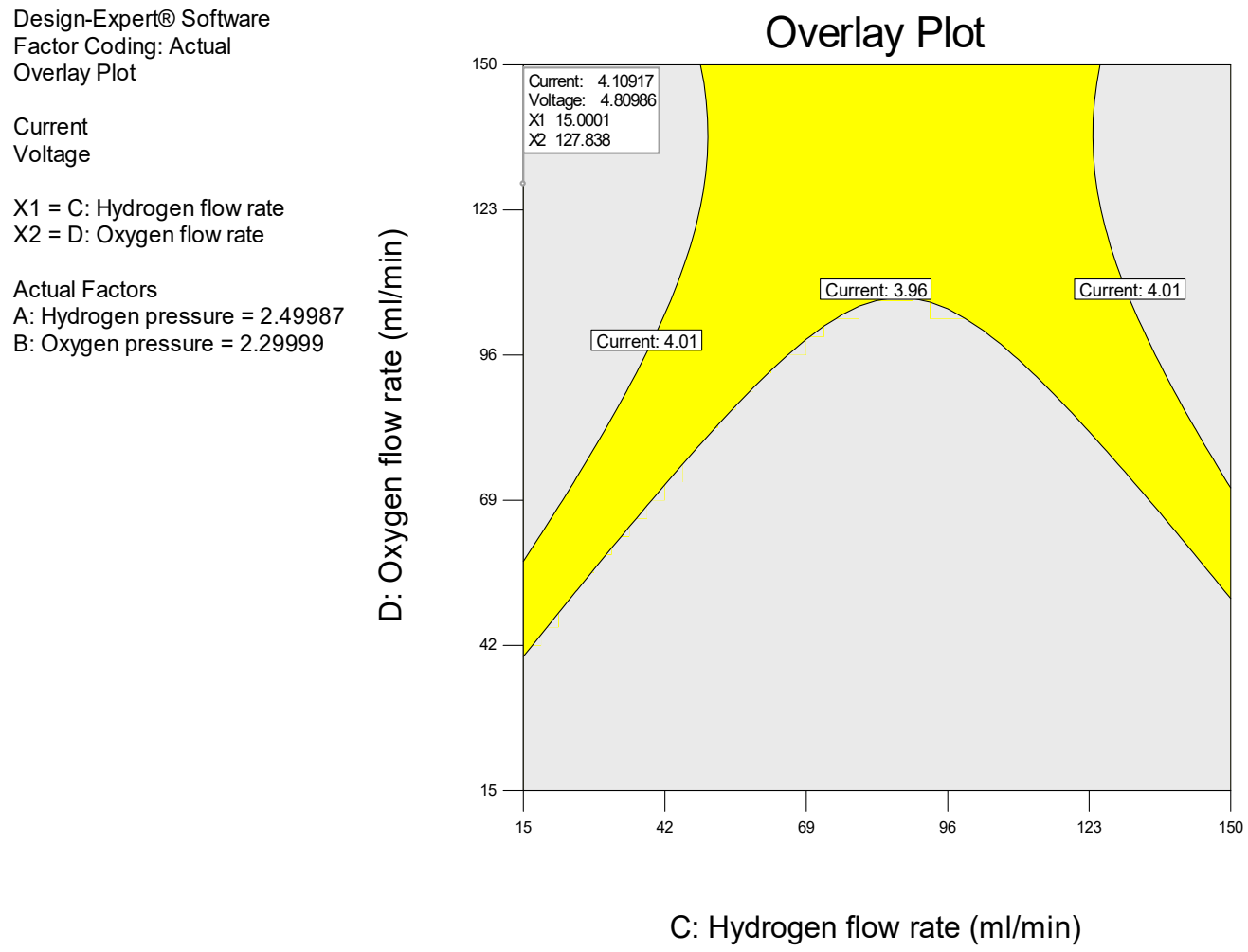

Figure 12. Performance of the fuel cell at varying operational conditions (a) Higher reactant pressure; (b) lower reactant pressure. 
For the world to generate energy that is highly efficient but environmentally friendly, many factors must be taken into consideration. For these new energy generation mediums to compete with existing ones like fossil fuels, the cost of running these new technologies must be critically investigated. The industrial community since 1970 has performed several researches to develop an energy-generation medium that is environmentally friendly. Today, the fuel cell, as explained earlier, is one of the key recommendations made by scientist around the world to meet this target. Several works are being carried out on fuel cell stack in order to improve their performance especially in relation to their internal heat and mass transfer. When the flow plate design allows even distribution of the reactant into the fuel cell, then the entire membrane surface area containing the platinum catalyst will go into electrochemical reaction and this in effect will cause more hydrogen ions and electrons to be released hence improving the cell performance. Performance of PEMFC is highly dependent on the rate at which electrons are released from the cell or the pace at which hydrogen gas (fuel) is consumed. A well-designed bipolar plate design will also aid in easy removal of the byproduct of the electrochemical reaction (water) and this will reduce the possibility of flooding or the number of dead zones in the fuel cells. The activation losses as well ohmic losses depicted in Figure 13 are likely to reduce. This report presents a detail investigation conducted on three (3) bipolar plate designs for a 5-cell stack fuel cell operated 60 and $80^{\circ} \mathrm{C}$. Design of experiment helped in the analysis of each of these designs for different operating conditions for each of the flow plate design under investigation. The best critical condition at which the fuel well should be operated to obtain the maximum output was also discussed.

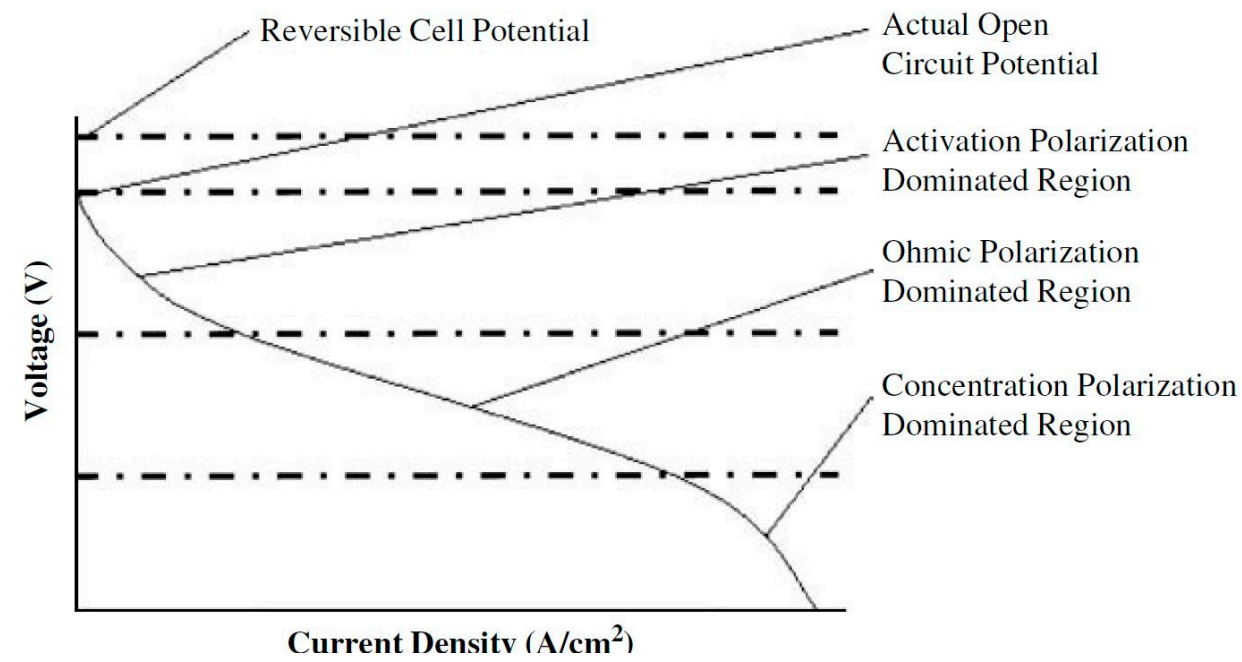

Figure 13. Polarization curve for a fuel cell.

\subsection{Voltage, Current and Power from Design of Experiments (DOE)}

Working fuel cell under normal circumstance should have a constant voltage but this is not a real-case scenario due to irreversibilities in the cell. The polarization curves generated for each design is shown in Figures 14-16. The activities occurring in the fuel cell encounters some resistances classified as activation overpotential, ohmic, mass concentration and fuel cross over and internal current overpotential. The cell operating temperature was maintained for all the experiment and the membrane electrode assembly used for all the entire fuel cell stack was same for all the bipolar plate designs. The opposition to the free movement of free electrons referred to as ohmic loss was slightly different for all the designs under investigation. This was because different bipolar plate designs have different surface area contact with the membrane electrode assembly (MEA), hence the more reactive gas go into reaction, and the better the performance of the PEMFC. 


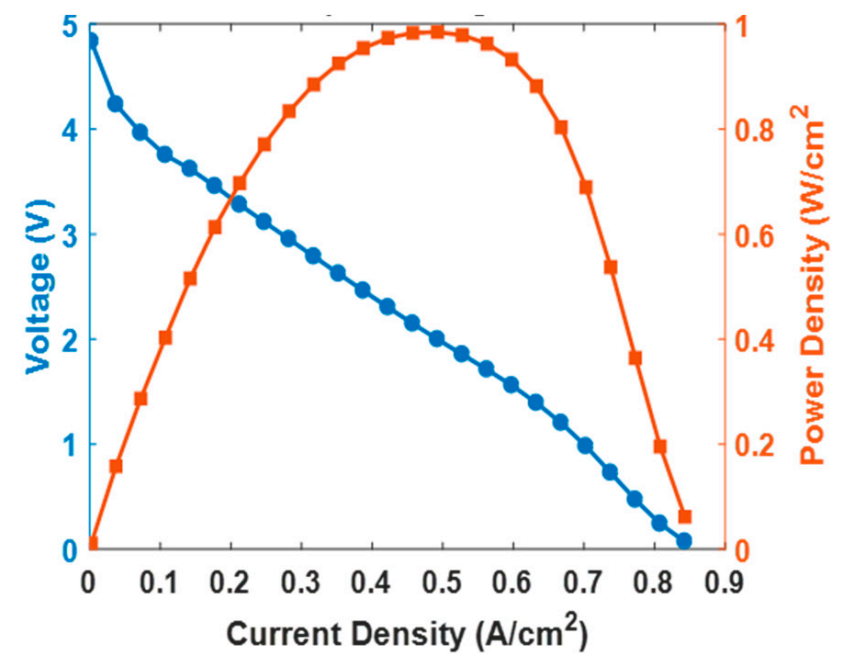

Figure 14. Polarization curve for spiral design bipolar plate.

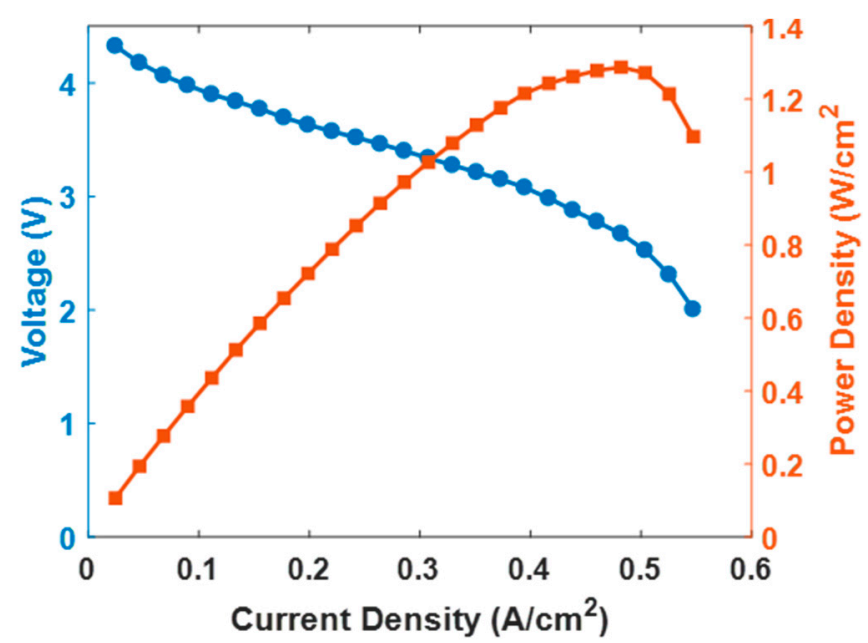

Figure 15. Polarization curve for parallel design bipolar plate.

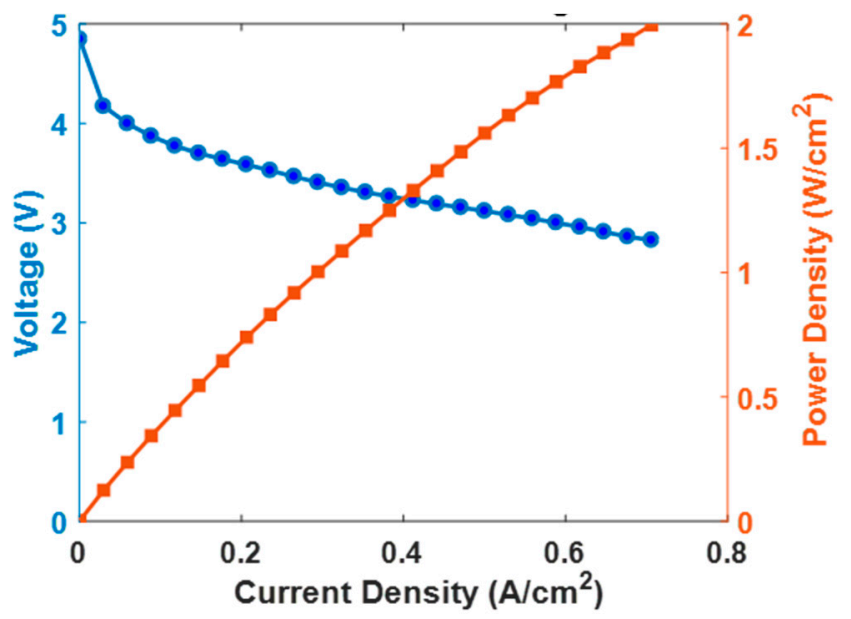

Figure 16. Polarization curve for interdigitated design.

Operating the cell stack at maximum oxygen velocity but low $\mathrm{H}_{2}$ velocity gave the highest OPCV. Actual OPCV is always less than the theoretical model because of the crossover of species from one 
electrode through the membrane and internal currents. The type of losses occurring in the fuel cell can also be represented by Equations (29)-(31).

$$
\begin{gathered}
V_{i}=V_{\text {rev }}-V_{\text {act-anode }}-V_{\text {act-cathode }}-V_{\text {ohmic }}-V_{\text {conc-anode }}-V_{\text {conc-cathode }} \\
E=E_{r}-\frac{R T}{\alpha_{c} F} \ln \left(\frac{i}{i_{0, c}}\right)-\frac{R T}{\alpha_{a} F} \ln \left(\frac{i}{i_{0, a}}\right)-\frac{R T}{n F} \ln \left(\frac{i_{L, c}}{i_{L, c}-i}\right)-\frac{R T}{n F} \ln \left(\frac{i_{L, a}}{i_{L, a}-i}\right)-i R_{i}
\end{gathered}
$$

Equation (30) can further be simplified to Equation (31) as shown below.

$$
E=E_{r}-\frac{R T}{\alpha F} \ln \left(\frac{i_{\text {ext }}+i_{\text {loss }}}{i_{o}}\right)-\frac{R T}{n F} \ln \left(\frac{i_{L}}{i_{L}-i}\right)-i R_{i}
$$

The voltage overpotential needed to overcome the activation energy for the reaction occurring in the fuel cell electrochemically is called the activation polarization. This usually occurs on the catalytic region of the PEMFC where reaction between the oxidant and the $\mathrm{H}_{2}$ occurs electrochemically. This loss is dominant at low current densities and it determines the effectiveness of the catalyst layer at any specific cell operating temperature. The complexity of this process cannot be overlooked because the reactive gases, the metallic catalyst (solid in nature) and the electrolyte must all be in good contact in other to yield the maximum output from the PEMFC. The platinum catalyst plays a crucial role of reducing the activation barrier but there is still loss in voltage because the rate at which oxygen goes into reaction is slow. Typical activation polarization is usually between 0.1 and $0.2 \mathrm{~V}$ and this reduces the voltage of a typical fuel cell to less than $1 \mathrm{~V}$. The internal current and cross over is a phenomenon dominated around the membrane electrode assembly (MEA). The membrane is designed to allow only protons to flow through them but very often some hydrogen and electrons flow through the membrane. It implies that not all electrons released can be captured. Hydrogen going through the membrane further indicates that few electrons will go through the external circuit connected to the fuel cell. These losses are negligible when the fuel cell is in operation but becomes significant when the current densities are low or at open circuit voltage. The current generated from the fuel cell is shown in Equation (32).

$$
i=i_{\text {ext }}+i_{\text {loss }}
$$

Hydrogen that goes through the electrolyte will finally form water which will not make the PEMFC highly efficient. The crossover of hydrogen is subject to the electrolyte properties like thickness, permeability and partial pressures. When a fuel cell has an open circuit voltage less than $0.9 \mathrm{~V}$, it means there is some level of hydrogen leakage.

\subsection{I-V Curves (Polarization Curves)}

The performance of a fuel cell can be determined using polarization curves (I-V Curves) generated for the current, power density as well as the voltage. The generated results showed different characteristic performance for each design. The experiment was conducted at room temperature with the minimum pressure of 0.7 bar. From the polarization curve obtained, the spiral design performed better compared to the other bipolar plate designs. Figure 14 shows the results obtained for the spiral design, while Figures 15 and 16 show the polarization curve for the parallel and interdigitated design respectively.

\section{Discussion}

Design of experiment was used in this investigation to determine the operational characteristics of proton exchange membrane fuel cell. The Box-Behnken approach was adopted in this work using four input variables. The variables were hydrogen pressure, oxygen pressure, hydrogen flow rate and oxygen flow rate. From the investigation it was observed that varying the operational parameters surrounding the fuel cell had effect on the overall performance of the cell. Again, the bipolar plate 
geometry design equally affects the hydrogen consumed during the electrochemical reaction, hence the overall operational cost of the cell. In spite of the benefits of using the spiral design, there are still issues in terms of the pressure drop of the gas that need to be addressed before commercialisation of this novel flow plate. Reducing the weight of the bipolar plate will also reduce the overall cost of the fuel cell, hence materials that are light in weight but electrically conductive can also be explored to improve the performance of the fuel cell. The coating of the bipolar plate to further improve the electrical conductivity but reduce its susceptibility to corrosion will also immensely change the future prospects of this novel technology.

\section{Conclusions}

The optimization of fuel cells involves taking into consideration several operational parameters to validate the best conditions to achieve the maximum output from the PEMFC. Design of experiment (DOE) helped in generating surface response for three (3) different bipolar plate designs (Spiral, parallel, interdigitated). The results obtained showed that the bipolar plate design and operational parameters affected the output characteristics from the PEMFC. A critical study of the analysis of variance (ANOVA) showed that the experiment was conducted in perfect agreement with an existing approach used in the literature [15]. The experimental results that were slightly odd were quickly highlighted and the experiment conducted again. The initial experiment was performed using a single PEMFC with serpentine flow channel obtained from fuel cell store in the United States. The obtained current from the single cell was $600 \mathrm{~mA}$ and $0.7 \mathrm{~V}$ as the voltage. The fuel cell was redesigned as a five-cell stack with three (3) different bipolar plate designs manufactured at the UWS mechanical workshop. The purchased fuel cell performance was low compared to results obtained in the literature. The work further investigated the best bipolar plate design with the optimal operational parameters that would yield the maximum performance from the PEMFC. The MEA, the GDL as well as the platinum loading on the MEA were all kept constant for all the experiment conducted for the three bipolar plate designs. The voltage obtained from all the three designs increased as the rate of oxygen increased at a lower hydrogen flow rate. The fuel efficiency was also dependent on the pace at which $\mathrm{H}_{2}$ was introduced into the flow channels of the PEMFC and consumed on the catalyst layer. The newly designed spiral or vein design showed better performance compared to the parallel and interdigitated design. The interdigitated design performed slightly well but the spiral design allowed more hydrogen gas to reach the catalyst layer faster and this phenomenon helped in the release of more electrons, making the spiral or vein design highly efficient. Even though the spiral design needs more modification to reduce the number of dead zones, it still gave the best performance compared to the serpentine design already existing on the fuel cell market and in the literature [16]. The interdigitated equally needs more modification to enhance the water management in any fuel cell when used as the flow plate design.

Author Contributions: Conceptualization: T.W. and A.G.O.; methodology, T.W.; software, T.W.; validation, A.G.O.; formal analysis, T.W.; investigation, T.W. and A.G.O.; resources, A.G.O.; Writing-Original draft preparation, T.W.; Writing-Review and editing, A.G.O.; visualization, T.W.; supervision, A.G.O.; project administration, T.W. All authors have read and agreed to the published version of the manuscript.

Funding: This research received no external funding.

Conflicts of Interest: The authors declare no conflict of interest.

\section{References}

1. Zhang, X.; Chen, S.; Xia, Z.; Zhang, X.; Liu, H. Performance Enhancements of PEM Fuel Cells with Narrower Outlet Channels in Interdigitated Flow Field. Energy Procedia 2019, 158, 1412-1417. [CrossRef]

2. Chen, H.; Song, Z.; Zhao, X.; Zhang, T.; Pei, P.; Liang, C. A review of durability test protocols of the proton exchange membrane fuel cells for vehicle. Appl. Energy 2018, 224, 289-299. [CrossRef]

3. Gang, B.G.; Kwon, S. All-in-one portable electric power plant using proton exchange membrane fuel cells for mobile applications. Int. J. Hydrog. Energy 2018, 43, 6331-6339. [CrossRef] 
4. Dhakate, S.R.; Mathur, R.B.; Kakati, B.K.; Dhami, T.L. Properties of graphite-composite bipolar plate prepared by compression molding technique for PEM fuel cell. Int. J. Hydrog. Energy 2007, 32, 4537-4543. [CrossRef]

5. Hu, Q.; Zhang, D.; Fu, H.; Huang, K. Investigation of stamping process of metallic bipolar plates in PEM fuel cell-Numerical simulation and experiments. Int. J. Hydrog. Energy 2014, 39, 13770-13776. [CrossRef]

6. Zhang, C.; Ma, J.; Liang, X.; Luo, F.; Cheng, R.; Gong, F. Fabrication of metallic bipolar plate for proton exchange membrane fuel cells by using polymer powder medium based flexible forming. J. Mater. Process. Technol. 2018, 262, 32-40. [CrossRef]

7. Afshari, E.; Ziaei-Rad, M.; Shariati, Z. ScienceDirect A study on using metal foam as coolant fluid distributor in the polymer electrolyte membrane fuel cell. Int. J. Hydrog. Energy 2015, 41, 1902-1912. [CrossRef]

8. Wilberforce, T.; Alaswad, A.; Palumbo, A.; Dassisti, M.; Olabi, A.G. Advances in stationary and portable fuel cell applications. Int. J. Hydrog. Energy 2016, 41, 16509-16522. [CrossRef]

9. Box, G.E.P.; Wilson, K.B. On the experimental attainment of optimum conditions. J. R. Stat. Soc. Ser. B Methodol. 1951, 13, 1-45. [CrossRef]

10. Paul, G. Mattews. Design of Experiments: Overview. Available online: http://thequalityportal.com/q know02.htm (accessed on 29 May 2020).

11. Benyounis, K.Y. Prediction and Optimization of Residual Stresses, Weld-Bead Profile and Mechanical Properties of Laser Welded Components. Ph.D. Thesis, School of Mechanical Engineering, Dublin City University, Dublin, Ireland, 2006.

12. Olabi, A.G.; Casalino, G.; Benyounis, K.Y.; Rotondo, A. Minimisation of the residual stress in the heat affected zone by means of numerical methods. Mater. Des. 2007, 28, 2295-2302. [CrossRef]

13. Benyounis, K.Y.; Olabi, A.G.; Hashmi, M.S.J. Multi-response optimization of CO2 laser-welding process of austenitic stainless steel. Opt. Laser Technol. 2008, 40, 76-87. [CrossRef]

14. Box, G.E.P.; Behnken, D.W. Some new three level designs for the study of quantitative variables. Technometrics 1960, 2, 455-475. [CrossRef]

15. Design-Expert Software, V7, User's Guide, Technical Manual; Stat-Ease Inc.: Minneapolis, MN, USA, 2005.

16. Carton, J.G.; Olabi, A.G. Design of experiment study of the parameters that affect performance of three flow plate configurations of a proton exchange membrane fuel cell. Energy 2010, 35, 2796-2806. [CrossRef] 